\title{
THE PALLET CONVEYOR SYSTEM APPLICATION IN THE INDUSTRIAL LINES - A NEW DESIGN SYSTEM WITH IMPROVEMENT OF PRODUCTIVITY
}

\author{
PRATIK P. GANDHI ${ }^{1} \&$ G. S. SHARMA ${ }^{2}$ \\ ${ }^{1}$ Research Scholar, Oriental University Indore, Madhya Pradesh, India \\ ${ }^{2}$ Dean Engineering \& Head, Oriental University Indore, Madhya Pradesh, India
}

\begin{abstract}
The design and operation of a high volume conveyor sortation system are important due to its high cost, large footprint and critical role in the system. In this thesis, we study the characteristics of the conveyor sortation system from performance evaluation and design perspectives employing continuous modelling approaches. We present two continuous conveyor models ("Delay and Stock Model" and "Batch on Conveyor Model") with different representation accuracy in a unified mathematical framework. Based on the Batch on Conveyor Model, we develop a fast fluid simulation methodology. We focus on the feasibility of implementing fluid simulation from modelling capabilities, algorithm design and simulation performance in terms of accuracy and simulation time. First, we model the performance evaluation problem as a class of dynamic network flow problems by using Delay and Stock Model. Not only does this model give us the performance metric, but it also provides us with an analytical form of the sub gradient of the performance metric with respect to the design parameters. Second, we adopt the Batch on Conveyor Model and employ fluid simulation as a performance evaluation tool. We investigate the approach on a two-segment tandem conveyor system which is the building block of more complex systems. For this system, we derive a sensitivity estimator by applying infinitesimal perturbation analysis (IPA) and study the performance of this estimator through numerical experiments.
\end{abstract}

KEYWORDS: Pallet, Conveyor Models, Sensors, Delay and Stock Model \& Time Performance

Received: Feb 25, 2019; Accepted: Mar 16, 2019; Published: Apr 16, 2019; Paper Id.: IJMPERDJUN201929

\section{INTRODUCTION}

In an automation demands efficiency, and conveyors are one technology to enhance the productivity of processing lines. No wonder then that conveyors have become integral components in all phases of the automation, assembly, and industrial markets. What's more, while some of the dominant global brands have been early adopters to embrace the full potential of conveyors; more companies of all sizes are taking a closer look at how they too can better integrate conveyor systems to ultimately improve entire lines.

Though integrating such conveyor systems can be daunting - especially those meant to become an integral part of larger processes - manufacturers offer help. The first step is to evaluate the application and determine the expectations for conveyor system. Even for this step, resources about to make this process easier.

Pallet conveyors coordinate tasks: The manufacturing environment inside facilities is much different than what it was a generation ago. Automation is now a prime driver behind the way products are produced. Many applications include both manual processes and robotic interaction ... so conveyors today must be engineered to 
meet these challenges. That's why pallet system, conveyors have become a popular choice [1-2-3].

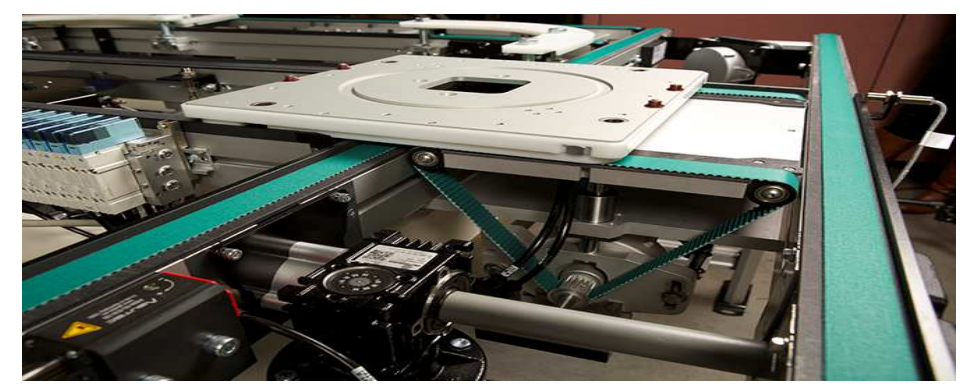

Figure 1: Manufacturing Environment

Pallet system, conveyors are suitable for many automation-focused applications that need exact movements and positioning of parts, as they can be setup or programmed to start and stop at specific intervals to synchronize with robotics or other processes. These conveyors dominate automotive-component manufacturing and other industries including medical devices, electrical and electronics, and product testing and inspection that require automated and manual assembly (or handling) of products.

Pallet system conveyors typically come on three different platforms to convey the pallet [3-4-5]:

- A dual-belt configuration powered by a common drive

- A flexible plastic chain or belt design

- A linear motor

Pallets can stop and raise up off the belts or rotate the pallet $90^{\circ}$ or $180^{\circ}$ to reposition product as needed. Companies using pallet-system, conveyors are leveraging their accuracy. These conveyors put products at exact locations — and conveyor lift and location stations deliver repeatability of 0.002 in. Pallets can come in either square, rectangle, or octagon shapes; they can make tight turns and travel up inclines or down declines as well.

\section{Pacing Conveyors to Stagger Items}

Another type of conveyor that's increasingly common in manufacturing automation and packaging are pacing conveyors. These conveyors take randomly spaced products and orientate them into even spacing for packaging, machine in feed, or other processes.

The system usually has two variable speed belts and a moveable conveyor junction. This two-belt design allows pacing conveyors to operate at a faster rate than a standard one-belt conveyor.

As randomly spaced products enter the conveyor, a photo eye detects the product spacing. Then a servomotor control automatically varies the conveyor speed and conveyor junction placement to evenly space product. Pacing conveyors are completely noncontact sand contains no guides, diverts, or plows. Usually these conveyors have HMI interfaces to let operators set the spacing, speed, and orientation of products. That in turn helps applications that require the merging multiple lanes together without product stops or gates. 


\section{Flexible Chain Conveyors for Tight Spaces}

Some application designs need products moved in and around equipment and machinery. Here, conveyors must be flexible and make tight turns. Flexible chain conveyors are a good fit here. Automated applications within processing and packaging, industrial, medical, life sciences, and health and beauty industries often operate in tight spaces or in plants that require product elevation changes (for storage and space management) so are benefit from integration of flexible chain conveyors.

In fact, the flexibility of these conveyors extends past the platform itself. Their ability to twist, turn and snake around tight places gives design engineers and plant managers the flexibility to easily integrate the conveyors with existing equipment.

\section{Precision Timing-Belt Conveyors}

Many industrial automation, product assembly, manufacturing, and packaging applications need product in exact spots on the conveyor at the right time. Precision timing-belt conveyors excel here. Powering the conveyor to deliver accurate alignment of time and distance are servomotors that provide indexing repeatability of $\pm 0.040 \mathrm{in}$. at a rate of 100 indexes per minute. This level of precision is critical — especially in robotic applications [6-7-8].

\section{SELECTING THE RIGHT PALLET CONVEYOR SYSTEM}

Clearly there are many conveyors engineered for automation-type applications, but the objective is to select the right one for a given application. Conveyors built to specification improve production-line efficiency and output. So there's no reason to settle for a conveyor that's shoehorned into application, especially when a system can be engineered to seamlessly integrate into a larger process.

But to do that requires an understanding of what the goals and expectations are for conveyors. In other words, what must the conveyors to do? Knowing this upfront establishes a good foundation for a successful conveyor installation.

Whether the conveyor system is to serve the operations of an OEM or integrator, a small family-owned shop, or a multinational business, there are common design concerns regarding new conveyor installations. Begin to outline the conveyor objectives by answering these questions: How will the conveyor system integrate with what the plant is trying to build. What is the height, weight and shape of the product(s) being moved. What's the targeted rate of production? How much space is available for the conveyors? Is space likely to be tight, needing conveyors to make sharp turns or go up inclines? Is the machine or production line manual or automated? Is the anticipated flow of production linear or oval [9-10$11]$.

Quantifying this information upfront helps get a more complete picture of the application - and define the project scope to let the conveyor supplier streamline the quotation process[12-13-14].

\section{APPLICATION EXPERTISE FOR PALLET CONVEYORS}

Consider the above questions to a vision how conveyors should interact with the processing line or project into which they're integrating. All the component within an assembly automations application (including conveyors) should work together optimize the overall operation. Answering the above questions can also identify where improvements in product flow and handling can be made. Such analysis may determine no improvements are necessary — and that's great. 
But if a planned conveyor system isn't quite meshing with other application systems, or it appears as though the target output is in jeopardy, reviews can help ... and in fact, this is where reputable conveyor suppliers prove their worth.

Perhaps more valuable than the actual conveyors are supplier knowledge and experience integrating designs for material handling and industrial automation. Collaborative discussions with conveyors supplier and identifying potential design road blocks are a great way to start. Some suppliers accept responsibility for the ultimate design and do the heavy lifting to supply conveyor systems that are specifically optimized for the application at hand.

Of course, collaboration doesn't necessarily result in custom conveyor designs - because after all, standards offerings are less costly than custom. But good supplier recommendations are typically based on using standard products as much as possible while integrating custom designs where needed to ensure reliability and flexibility. That's why a onesize-fits-all conveyor isn't always the best choice. The goal of a well-designed conveyor system is to serve the process ... and not to fit the process to the conveyor [15-16].

\section{Pallet Handling Conveyor Systems}

Specializes in pallet conveyor system equipment that is designed for high-volume and heavy-duty performance. We offer a wide range of rollers, drives, and frame construction. Commonly in pallet handling systems the capacity is 3,000 pounds. Typical pallet systems are design for conveyance of the following:

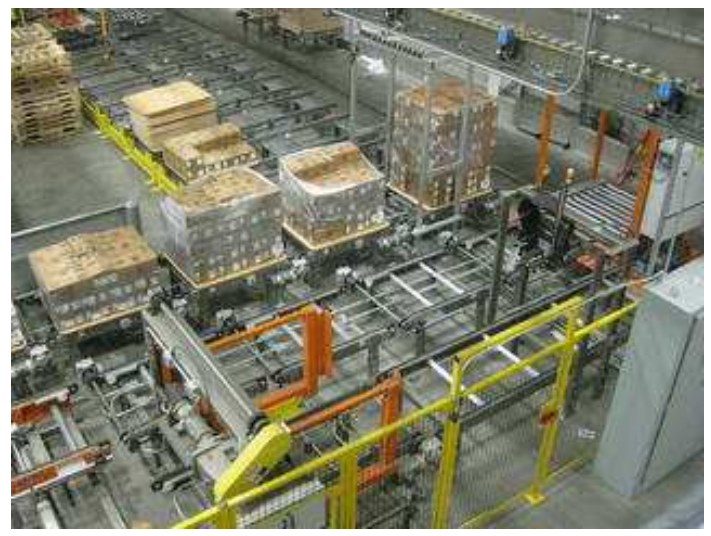

Figure 2: Pallet Handling Conveyor Systems

- GMA Pallets

- $\quad$ CHEP Pallets

- PECO Pallets

- $\quad$ Euro Pallets

- Returnable containers

- Custom fixtures, racks, or assemblies

\section{Pallet Handling Conveyors}

- Chain-Driven Live Roller Conveyors: The IKI line of chain-driven live roller conveyors is capable of handling loads of up to 50,000 pounds. Common applications include palletizing, metal processing, heavy engine assembly 
and test, vehicle assembly, and large-volume distribution applications. Our chain driven live roller conveyor is built with precision components, resulting in a longer service life as compared to our competitors.

- Motor-Driven Roller (MDR) Conveyors: Pallet load handling, and other heavy-duty applications, our motordriven roller conveyors use advanced motorized roller technologies to create carefully controlled drive zones that support process automation functions.

- Gravity Roller Conveyors: These affordable, non-motorized options are an ideal solution for controlling costs and providing simple accumulation systems. Versatile and lightweight with an extended service life, our gravity roller conveyors are used for a broad range of applications. These include warehousing and distribution management, materials handling, food processing, shipping and receiving, and manual product assembly. We commonly use gravity roller conveyor as a pickup point in automatic pallet handling systems to minimize the potential effects of damage from fork tuck interaction with the conveyor.

- Chain Conveyors: Chain conveyors can be a great solution for handling GMA type pallets with the 40" dimension leading, handling custom steel fixtures, or skids. Chain conveyor is commonly used when pallet bottom boards are perpendicular to the flow, creating a segmented running surface. IK chain conveyor for typical pallet conveyor systems are designed with configurable features such as drives, chains, chain running surfaces. Standard accessories such as guides, stops, and justifiers are available to provide a complete solution.

- Turntables: Turntables are often used in pallet handling systems to merge or divert pallet loads between destinations or sources. The turntable will reorient the load based on rotation degree, but will maintain the orientation in relationship to the conveying media. This is beneficial in applications where maintaining the orientation is required or beneficial functionally or financially.

- Pallet Dispensers \& Collectors: Pallet dispensers are used in applications where a single pallet needs to be presented separated from a stack. A pallet collector performs the opposite function, handling a single pallet and placing it in a stack Industrial Kinetics offers multiple styles of pallet dispenser which is influenced by the pallet type, available space, accumulation requirements, and system configuration.

- Pallet Inserters \& Double Stackers: The purpose of a pallet inserter or double stacker is to lift a load and insert a pallet or other load under the first load. This equipment is commonly used to double stack palletized loads for pickup by AGV or forklift. This can help reduce forklift or AGV time / cost by transporting two unit loads at a time and by having the loads stack automatically prior to forktruck or AGV arrival. Pallet inserters are often used in packaging lines that were not design to include pallet handling. Often at the end of these lines the unitized loads are handled at the end of a line of clamp truck, which may damage the load. Inserting a pallet can eliminate the damage to the product as a result of clamp truck load handling.

- Vertical Reciprocating Conveyors: Vertical lifts are applied in pallet handling systems where loads are transported between floors or levels of a system. Speed, rate, load rate, and size are considerations in configuring the equipment for the application.

- Roller and Chain Transfers: Pop up chain or pop up roller transfers are incorporated into pallet handling systems to merge, sort, or change the direction of travel. IK offers a variety of lift options for the vertical travel as 
well as a variety of conveyor types. Lift options include cylinder lifts, air mount lifts, linkage lifts, and gear motor cam lifts.

- Transfer Cars: Transfer cars are often used in pallet handling systems to distribute or collect materials in parallel processes, or between processes. Some common examples of this is merging multiple palletizing lines to a common stretch wrapper cell. Another example would be using a transfer car in an assembly operation that includes few operations longer than the line TAKT time. The transfer car allows material to be conveyed into two or more parallel processes with minimal equipment to allow the TAKT time to remain at the overall line rate. This is common in assembly operations where testing can take longer than the TAKT time for assembly alone.

- Turning Cross Conveyors: Industrial Kinetics turning cross are commonly used in labeling, strapping, wrapping, packaging, \& assembly operations to reorient a load on a conveyor system.

- Shuttle Conveyors: Industrial Kinetics shuttles are used to remove or sort unit loads from a main line to a workstation, input, and/or multiple transport lines. This equipment is commonly applied in test operations \& ASRS or stretch wrapper line input operations. The benefit to this equipment over a chain transfer is the ability to move the loads to three locations, \& the ability to handle loads handling characteristics that are difficult for chain transfers.

\section{THE PROBLEM DEFINITION}

As described in the introduction the main problem that needs to be solved during this project is to automate the lamination process of plastic boards, which is at the moment done semiautomatic ally. Solving that problem requires a design of automated production/palletizing line serving an existing lamination machine, that must need no more than two workers to operate. Solving this problem includes a number of subtasks. A successful result to this engineering project will be full production drawings and specifications of described production line from which the line could be manufactured, and implemented into production with no major setbacks. An overall approach and more precise problem definition on automating the production was given by the client's company. In cooperation with the client, more detailed subassignments were developed and a general design concept was specified. The production line is intended to laminate plastic boards with about 3,1-meter length The boards are a bit longer than the final 3-meter product - that is because the edges of the boards need to be cleanly cut, which is done later in the production process after they have had some time to cure. In case of some board types, both sides need to be laminated. Client's experiments have shown that it cannot be done at the same time or shortly after, as the boards need some time to cure to guarantee the lamination's quality [17].

\section{RESEARCH OBJECTIVE}

Based on our literature summary, we study the sortation system from performance evaluation and design perspectives. Because of the prospects of reducing the computational effort in simulation and leading to tractable models in optimization, we take continuous modelling approach throughout the study. First, we want to create a rigorous and uniform mathematical framework to present various continuous conveyor models. It will serve as a concrete base to develop simulation and optimization models and to conduct sensitivity analysis. We also want to investigate differences on representation accuracy of these models and analyze the rationale of generating this difference. 


\section{WHY INVEST IN AUTOMATED CONVEYOR SYSTEMS?}

Material handling conveyors to add speed, efficiency and safety to any warehousing and shipping operation:

- Automated conveyors enable faster transport of products from production to storage to the staging area, especially in warehouse configurations with a great deal of distance to be covered that are nonlinear, and/or involve vertical movement.

- Along with greater speed, which can dramatically increase throughput, automated conveyor systems move products more smoothly, reducing or eliminating product and pallet damage. Product damage, especially when undetected, results in returns, reshipments, and ultimately, damage to customer relationships — or even lost customers.

- In addition to speed and damage reduction, automated warehouse conveyor systems enable personnel to replace physically demanding, repetitive labor with tasks that add more efficiency to warehouse and shipping operations — and last but definitely not least, help to reduce injury, absence from work and downtime.

\section{MATERIAL HANDLING CONVEYORS MOVE YOUR PRODUCTS SAFELY AND EFFICIENTLY}

Not all conveyor system manufacturers welcome customization — but we do! All of our pallet conveyor systems can be designed to meet your needs in terms of heights, widths and speeds. Our in-house design and engineering teams utilize the latest parametric modelling software (Solid Works), which delivers a high level of design flexibility. Our warehouse conveyor solutions offer more functionality and protect against breakage, making your material handling process more efficient and ultimately, more profitable for your business.

\section{WAREHOUSE CONVEYOR SYSTEMS PRODUCT LINE}

Westfalia offers a multitude of industrial conveyor systems to transport your products, including bag handling, specialized conveyors and pallet handling conveyors.

\section{Bag Handling Conveyors}

- Bag closer conveyors

- Belt conveyors

- Compact length conveyors

- Incline transport conveyors

- Packer discharge conveyors

\section{Specialized Conveyors}

- Accumulation conveyors and feeders

- Bag flatteners

- Bag knock-down turner conveyors

- $\quad$ 90-degree curve conveyors 
- Reject unit conveyors

- $\quad$ Settler conveyors

- Transfer unit conveyors

A working concept like this implies several tasks the production line must perform also considering requirements of an existing Lamination machine:

- Queuing the input and output pallets and transfer the empty ones from input to the output - necessary so the operation will not be interrupted until the forklift operator loads a new pallet

- De palletizing the boards

- Separating the stack into individual boards that are sequentially fed to Lamination machine

- Boards must be fed into Lamination machine with specified gap between them

- Cutting the laminate between the board to separate them.

- $\quad$ Flipping the boards over, optionally must be able to turn it off.

- Collecting the individual boards, and palletizing them.

- Operational with different board shapes and sizes

\section{Pallet Conveyor Systems}

We offer both fixed direction palletized conveyer systems and change of direction units. Both types provide reliable, innovative pallet handling that transports and accumulates pallets smoothly.

The consequence: Mechanics innovation with optimum

- Cost-efficiency

- $\quad$ Energy-efficiency

- Ramp-up time

- Availability

- $\quad$ Life-time-costs

- $\quad$ Stability

- Wear

- Maintainability

- Maintenance Intensity and Spare parts consumption

\section{CONCLUSIONS}

Those production line's sub-assemblies were then described and analyzed one by one, in a logical order. First, a machine part responsible for queuing the input and output pallets was discussed and realized in a form of a roller conveyor. 
From that, a part lifting the boards off the stack on the pallet layer by layer or forming a stack as in case of at output side was described. The problem was solved using a 2-axis gantry with vacuum area grippers to lift the boards. The board layer is placed on a chain conveyor to feed the next stage - boards are separated by a gravity operated mechanism. The individual boards are then fed into Lamination machine with the specified gap between them - it required to design a separate conveyor moving the boards along its length, with a board gap adjusting system. Receiving the boards after lamination and cutting the laminate between the boards was discussed next - it required a conveyor after Lamination machine, with a cutting mechanism and an identical gap adjuster system as described above. After that, it is necessary to flip the boards over - it was solved in a gravity assisted manner as in case of separating the boards. The next stage is responsible for gathering the individual boards to a layer again. It was realized by identical Board layer conveyor as described above, but with some configuration differences. From that to the end, the same assemblies are used as at the input side. One more machine part was discussed finally, the one responsible for transferring the empty pallets from the input to the output. From each of those production line parts, a number of engineering problems emerged and were solved in succession. Finally, an automation and control of this production line was discussed, and in appendices three examples of production drawings are displayed. In the near future, the production line's design together with production drawings and other documentation will be finalized and after that, a first prototype will be built, and changes made into the design from lessons learned. After that, a number of identical production lines are planned to be built.

\section{ACKNOWLEDGMENTS}

In this research work made invaluable contributions to the fulfilment of my research guide Dr. G. S. Sharma, Dean Engineering and Technology Head, Oriental University, Indore for he understood by us all the way directed as from start to end. I would like to thank Dr. K. L. Thakral Chancellor, Oriental University Indore, Dr. Devendra Pathak, Vice Chancellor, Oriental University Indore, Prof. (Dr.) Dhruva Ghai, Pro-. Vice Chancellor, Oriental University Indore. I would like to express Prof. Kundan Gupta, Head, Department of Mechanical Engineering, Oriental University Indore. For the completed research help and guidance. I would like to thank our parents, family members, wife with my daughter and friends for their support.

\section{REFERENCES}

1. Nasif Hassan Khan, Deb Kumar Sarkar, Asif Siddique, Md. Mamunur Rahman, Swarup Chakraborty, Fabrication of a Conveyor Belt with Object Sorting and Counting Facility, International Journal of Advancements in Research \& Technology, Volume 6, Issue 5, May-2017, ISSN 2278-7763,60-64.

2. Vijay M. Patil Nitesh kumar A. Vidya Roshan L. Katkar Piyush S. Pande, Type of Conveyor System: A Review, IJSRD International Journal for Scientific Research \& Development| Vol. 2, Issue 12, 2015 | ISSN (online): 2321-0613,305-307.

3. Uday. D. Bharitkar, Sachin. R. Kale, Akash. V. Agarwal, Bhavik. R. Lodha, Saurabh. P. Deshpande, A Structured Approach To Material Handling System Selection And Specification For Manufacturing, International Journal Of Advances In Mechanical And Civil Engineering, Issn: 2394-2827,91-95.

4. F. I. Malek, M. Muaz, S. Rubiah, M. N. Mansor, M. A. Muda, Design And Development To Improve Mechanism Of Conveyer System Part 1, Integrated Design Project Conference (Idpc) 2015, Faculty Of Mechanical Engineering, Universiti Malaysia Pahang, 11 Dec 2015,1-12.

5. Pradnyaratna A Meshram, Dr. A R Sahu, Design, Modeling and Analysis of conveyor system used for transportation of Cartons, International Journal of Research in Advent Technology, Vol.4, No.1, January 2016 E-ISSN: 2321-9637,79-88. 
6. P. S. Solankar, Design And Analysis Of Roller Conveyor For Weight Optimization By Using Composite Material, International Journal Of Engineering Sciences \& Research Technology, Solankar, 5(2): February, 2016] Issn: $2277-$ 9655,269-278.

7. Samadhiya, Rohit., \& Singhal, P. (2013). the design of I shaped defected ground structure directional coupler. International Journal of Advanced Engineering and Technology, 2, 55-58.

8. M. Y. Dakhole, Prof. P. G. Mehar, Prof. V. N. Mujbaile, Design of Automated Moving Fixture for Conveyorised Special Purpose Machine, International Journal of Engineering Research \& Technology (IJERT), ISSN: 2278-0181, Vol. 1 Issue 5, July-2012,1-8.

9. Hirendra Kumar Verma, Sakshi Dewangan, Praveen Kumar Thakur, Dharmendra Sahu, Rinkey Sahu, Fabrication Of Automated Conveyor System For Material Handling Based On Ldr, International Journal Of Mechanical And Production Engineering, Issn: 2320-2092, Volume- 5, Issue-11, Nov.-2017,10-15.

10. Mr. Sanket Pandit, Dr. A. G. Thakur, A review paper on Redesign of Gravity Roller Conveyor System for Weight Reduction through optimization, International Journal of Scientific \& Engineering Research, Volume 6, Issue 2, February-2015, ISSN 2229-5518,499-503.

11. Konakalla Naga Sri Ananth, Vaitla Rakesh, Pothamsetty Kasi Visweswarao, Design And Selecting The Proper Conveyor-Belt, International Journal Of Advanced Engineering Technology, E-Issn 0976-3945,43-49.

12. Chimezirim O. Aliworom, Lazarus O. Uzoechi, Mathew Olubiwe, Design of Fuzzy Logic Tracking Controller for Industrial Conveyor System, International Journal of Engineering Trends and Technology ( IJETT ) - Volume 61 Number 2 - July 2018,65-71.

13. Abhijit Gaikwad, Yogesh Raut, Jitendra Desale, Akshay Palhe, Govinda Shelar, Prof. Shreekant Pawar, Design and Development of Automated Conveyor System for Material Handling, IOSR Journal of Mechanical and Civil Engineering (IOSR-JMCE) e-ISSN: 2278-1684, p-ISSN: 2320-334X, PP 31-34.

14. G Swaminathan, S D Kumar, Dr A Mathivanan, Dr K C Udaiyakumar and E Vijayaragavan, Design and development of multi drop auto-walk, International conference on Advances in Mechanical Engineering (ICAME 2018), IOP Conf. Series: Materials Science and Engineering 402 (2018) 012153 doi:10.1088/1757-899X/402/1/012153,1-8.

15. M. Y. Dakhole, Prof. P. G. Mehar, Prof. V. N. Mujbaile, Design And Analysis Of Dedicated Fixture With Chain Conveyor Arrangement For Multistage Special Purpose Machine, International Journal of Engineering Research and Applications (IJERA) ISSN: 2248-9622, Vol. 2, Issue 5, September-October 2012, pp.181-192.

16. Sivakumar, S., Ranjithkumar, N., \& Ragunathan, S. (2013). Design and development of down draft wood gasifier. International Journal of Mechanical Engineering, 2(2), 1-10.

17. Suhas M. Shinde and R. B. Patil, Design and Analysis of a Roller Conveyor System for Weight Optimization and Material Saving, International Journal on Emerging Technologies 3(1): 168-173(2012), ISSN No. (Print) : 0975-8364. 